of, and care for, people with mental disorders, a strong case needs to be made not to ignore middle-income countries, where relatively low levels of investment have the potential to achieve great change. For example, Central Asian countries are keen to jointly develop a mental health workforce training institute. Expertise developed in Turkey, Ukraine or Georgia could be shared and accelerate progress elsewhere. It is frustrating how difficult it is to find support because of a combination of the misleading label of 'middle income', the requirement of sustained funding, and the difficulty to construct and sustain initiatives that cross borders. A strategic perspective focusing on potential benefits, rather than geography and superficial categories, might lift the quality of life of many of the most vulnerable people, their families and communities.

\section{References}

European Commission (2016) EU Framework for Action on Mental Health and Well-being. Available at https:/lec.europa.eu/health/ mental-health/framework_for_action_en.

World Health Organization (WHO) (2015a) The European Mental Health Action Plan 2013-2020. WHO Regional Office for Europe. Available at http://www.euro.who.int/_data/assets/pdf_file/0020/ 280604/WHO-Europe-Mental-Health-Acion-Plan-2013-2020.pdf.

World Health Organization (WHO) (2015b) Mental Health Atlas. WHO. Available at www.who.int/mental_health/evidence/atlas/ mental_health_atlas_2014/en.
SPECIAL PAPER

\title{
Supporting community-based care and deinstitutionalisation of mental health services in Eastern Europe: good practices from Bosnia and Herzegovina
}

\author{
Enrichetta Placella
}

Health Advisor, Swiss Agency for Development and Cooperation. Email: enrichetta.placella@eda. admin.ch

\section{Conflicts of interest: None.}

doi:10.1192/bji.2017.36

(c) The Author 2018. This is an Open Access article, distributed under the terms of the Creative Commons Attribution-

NonCommercial-NoDerivatives licence (http://creativecommons. org/licenses/by-nc-nd/4.0/), which permits non-commercial re-use, distribution, and reproduction in any medium, provided the original work is unaltered and is properly cited. The written permission of Cambridge University Press must be obtained for com mercial re-use or in order to create a derivative work.
In Eastern Europe, the Swiss Agency for Development and Cooperation is supporting various post-communist states in reforming their mental health systems to ensure equal access to high-quality services in communitybased settings. The approach and new care models introduced have proven successful in most of these countries, one of which is Bosnia and Herzegovina.

Bosnia and Herzegovina has experienced a sharp increase in mental disorders over the past 20 years. Much of the population is still suffering from the consequences of the war that ravaged the Balkans in the 1990s (Priebe et al., 2010). The most common mental disorders are depression, anxiety and disorders related to stress or domestic violence, as well as some more serious pathologies such as acute psychotic conditions and dementia. Of particular concern is alcohol and substance misuse among young adults suffering from transgenerational trauma in relation to the conflict. (On intergenerational transmission of trauma in general, see also Bowers \& Yehuda (2016), Devakumar et al. (2014) and Jordanova (2012).) These disorders are exacerbated by high unemployment and widespread impoverishment. An ageing population and increased life expectancy have led to an upsurge in mental health problems that tend to affect the elderly, in particular, dementia.

Prompted by a wave of deinstitutionalisation in mental health services across Europe since the 1970s, Bosnia and Herzegovina launched a comprehensive reform of its mental health services around 10 years ago, with a view to finding a balance between out-patient or in-patient care and the development of community-based services. Efforts to phase out mental asylums as an intervention model and to reduce the rate of hospital admission pose a real challenge in a context where public attitudes to those experiencing mental illness still result in stigmatisation and social exclusion. The Swiss Agency for Development and Cooperation has supported this reform since 2010 in the country's two political entities (Federation of Bosnia and Herzegovina and Republika Srpska), in partnership with the Swiss cantons of Jura, Fribourg, Bern and Geneva.

\section{An integrated approach with high-quality care}

As in Moldova and, more recently, in Ukraine, Swiss support in Bosnia and Herzegovina aims to promote equal access to health services and to improve the health and well-being of people living with a mental illness or those at risk of developing a mental disorder. Seeking a comprehensive 
approach, it also includes measures to reduce risk factors, ensure continuity in community-based care, and to fight stigmatisation and improve the social inclusion of people with mental health issues, working alongside social services, the police and educational institutions. A network of 72 community mental health centres has been established across the country.

The approach is based on interventions at three levels: the administrative and legislative framework, the provision of health services, and within the community itself. It encourages patients and the general population to demand high-quality services at an affordable price. Its work is based on an extensive network of partnerships with, for example, Swiss experts and institutions, central, federal and local authorities, professional associations, accreditation agencies and patient associations.

The first phase of the programme was devoted to adapting the legal and administrative framework for providing community-based mental health services; getting this care covered by health insurance was a major achievement. Moreover, a new law was enacted to require all institutions admitting patients with mental disorders to undergo regular inspections by independent bodies. Staffing requirements for the community mental health centres were laid down by the relevant authorities. Accreditation agencies in both political entities received training in capacity building, and the centres received support in the certification process and in applying the new standards.

The new centres set up under the programme provide high-quality services wholly within the primary care setting. They offer new forms of therapy with reasonable waiting times, made possible by the establishment of multidisciplinary teams comprising a psychiatrist, a psychologist, a nurse and a social worker. These teams also run public health and prevention campaigns within the community. The Swiss cantons involved provide considerable technical assistance in relation to occupational therapy and new patient management strategies, such as case management. A partnership with the public health institutions of the country's two entities has organised nationwide campaigns to tackle depression and anxiety. As a result of such joint activities, hospital admission rates for people with a mental illness have decreased by $30 \%$ since the start of the interventions.

\section{Reducing stigmatisation and improving social integration}

The approach also includes coaching by an internationally acclaimed psychiatrist specialising in countering stigmatisation of and discrimination against people with mental health problems. Patient associations have been set up or revived, and their members have received personal development training to help them share and talk about their experience and rebuild their selfesteem. New forms of therapy have helped most patients return to society, and some have even resumed their work.

This large-scale awareness campaign has helped change public attitudes to people with a mental disorder. A wider range of people are now interested in a better understanding of these pathologies, and journalists are less prejudiced when dealing with the subject. Mental health has become an issue covered by television debates and reports. Professional caregivers now interact with their patients with more empathy and respect.

By fostering equal access to services and promoting closer cooperation between local authorities and their communities, as well as increased patient participation in healthcare decisions and the development of shared social values (i.e. against stigmatisation), the programme helps to build social cohesion in a context where many factors tend to undermine such integration.

\section{Major challenges and opportunities}

Specific measures are being explored to guarantee the sustainability of the facilities put in place by the programme. The same applies to supervision of service quality, organisational capacity building and professional skills development for staff. Priority is given to supporting national institutions to ensure that they can perform these tasks. For example, professional associations that are better structured could have a key role in training and the quality assurance system, resulting in a more unified advocacy system.

To improve performance, the project intends to develop the management capacity of staff, e.g. in integrated human resources and business planning, financial management, monitoring and evaluation, negotiation and communication. A culture of quality and the associated benefits is encouraged so as to guarantee compliance with the standards developed and facilitate the re-accreditation process. Other current priorities include staff protection measures and better working conditions, particularly to reduce the risk of workplace stress.

There is now also increased collaboration among the various local actors, such as the healthcare facilities and the social and educational sectors, and increased dialogue with the municipalities so as to ensure continuity of care and keep the associated costs under control.

To ensure better coordination and proactive collaboration with the psychiatric hospitals, there are plans to improve the referral system and build mutual trust in a society that still has some deep-rooted reservations about the deinstitutionalisation of mental health services.

The programme has invested vast resources into strengthening the institutions responsible for drawing up and implementing national prevention programmes for mental disorders. These structures still have limited capacity, however, with highly fragmented activities and only occasional contact with the community mental 
health centres. Moreover, the public awareness and prevention campaigns run by the staff of these centres within the community are not organised as part of any structured framework, and are not officially planned or monitored.

There are plans to strengthen the patient associations by improving their structure and increasing contact with the umbrella organisations, professional associations and the institutions engaged in defending the rights of patients facing discrimination. Opportunities for social entrepreneurship are also being explored. Given that individuals with mental disorders tend to adopt higher-risk lifestyles, awareness campaigns regarding tobacco and alcohol consumption and balanced nutrition will also be run within the associations.
It is hoped that the process adopted for the reforms of mental health services in Bosnia and Herzegovina will be applied in other Eastern European countries to move from institutional care to community-based approaches.

\section{References}

Bowers M. E. \& Yehuda R. (2016) Intergenerational transmission of stress in humans. Neuropsychopharmacology, 41(1), 232-244.

Devakumar D., Birch M., Osrin D., et al (2014) The intergenerational effects of war on the health of children. BMC Medicine, 12, 57.

Jordanova K. (2012) Transmission of traumatic experiences in the families of war survivors from Bosnia and Herzegovina. Contemporary Issues, 5(1), 52-60.

Priebe S., Bogic M., Ajdokovic D., et al (2010) Mental disorders following war in the Balkans: a study in 5 countries. Archives of General Psychiatry, 67(5), 518-528.

\title{
SPECIAL PAPER \\ Bearing the cost of the American dream: reflecting on street homelessness in America
}

\author{
Parashar P. Ramanuj
}

Consultant Liaison Psychiatrist, Royal National Orthopaedic Hospital, London, UK; email p.ramanuj@doctors.org.uk

Conflicts of interest. This reflection was based on my time spent in America as a 2015/2016 Harkness Fellow in Health Care Policy and Practice. The

Fellowship is administed by The

by The

Commonwealth Fund, a private

independent foundation based in New York City. The views pre-

sented here are my own and not necessarily those of The

Commonwealth Fund, its direc-

Coms, officers or stuff. This mant

This manu-

script developed from a talk given

to the UK Harkness Alumni

Association at the Health

Foundation in London.

Acknowledgements. I thank the reviewer and Dr Howard Ryland, Mr Luke O'Shea and Prof George Ikkos for their helpful comments on earlier drafts of this

manuscript.

doi:10.1192/bji.2017.32
This paper is a British psychiatrist's personal reflection of the treatment of homeless people in American societies. Drawing upon theories of social distance, exclusion, discrimination and internalised stigma, this reflective piece suggests that homelessness is one price that certain societies pay to invest in the notion of individualised success and self-sufficiency. In reflecting on his own dissonance, the author argues that these societal processes exert a powerful influence on us as individuals, even if we as psychiatrists might think that our understanding confers on us a certain level of understanding.

For many, New York conjures up images of the Statue of Liberty, the Empire State Building and the bright lights and signs of Times Square. It does for me too; but having lived there for a year, mixed with these images are signs of a different nature. Some are pleas: 'I'm hungry and homeless. Please help.' Others, prayers: 'Hungry and Homeless. God Bless.' Some, simple parables: 'A good deed is rewarded.' Others still, reveal something of the person behind the sign: 'Cold and Hungry. Victim of domestic violence. 3 children.' And then there are those who need no written signs: those people who are ragged, dishevelled, mumbling, singing and dancing or glowering from sunken eyes but not quite seeing. I would see them every day on my way to work at the New York State Psychiatric Institute in upper Manhattan, on the subways and the streets, until I too stopped seeing.

\section{Un-seeing}

Homelessness has a broad meaning. Street homelessness refers to people who 'routinely find themselves on the street during the day with nowhere to go at night' (Diaz, 2006). It incorporates the term rough sleepers (people who sleep in the open air or places not designed for human habitation) as well as those who use temporary shelters, prisons and hospitals. Statistics on the number of rough sleepers are woefully inadequate, but best estimates suggest there were between 3000 and 4000 street homeless people in New York in 2016 (NYC Open Data, 2017). This is equivalent to the entire street homeless population of England for the same year (DCLG, 2016).

However, my epiphany came not in New York, but in Skid Row. This is one of the most impoverished areas of Los Angeles, with one of the greatest concentrations of street homeless people in America. I was visiting the (remarkable) Skid Row Housing Association, and my journey through the neighbourhood took me through street after street of simple tarpaulin tents with people in flagrant psychosis outside or intoxicated in the gutters. What was most astonishing was that 